\title{
A third of dying patients do not have end-of-life discussions with a physician: A nationwide registry study
}

\section{Original Article}

Cite this article: Melin-Johansson C, Sveen J, Lövgren M, Udo C (2022). A third of dying patients do not have end-of-life discussions with a physician: A nationwide registry study. Palliative and Supportive Care 20, 357-362. https://doi.org/10.1017/S1478951521000973

Received: 19 March 2021

Revised: 1 June 2021

Accepted: 8 June 2021

\section{Key words:}

Communication; End of life; Older people; Palliative care; Quality indicators;

Register study

\section{Address for correspondence:}

Christina Melin-Johansson,

Institution of Nursing Sciences,

Mid Sweden University, Kunskapens väg 8, 83125 Östersund, Sweden.

E-mail: christina.melin-johansson@miun.se (c) The Author(s), 2021. Published by Cambridge University Press. This is an Open Access article, distributed under the terms of the Creative Commons AttributionNonCommercial-NoDerivatives licence (https://creativecommons.org/licenses/by-ncnd/4.0/), which permits non-commercial re-use, distribution, and reproduction in any medium, provided the original work is unaltered and is properly cited. The written permission of Cambridge University Press must be obtained for commercial re-use or in order to create a derivative work.

\author{
Christina Melin-Johansson, R.N., PH.D. ${ }^{1,2}$ (D), Josefin Sveen, PH.D. ${ }^{2,3}$, \\ Malin Lövgren, R.N., PH.D. ${ }^{2,4,5}$ and Camilla Udo, PH.D. ${ }^{2,6,7}$
}

\begin{abstract}
${ }^{1}$ Institution of Nursing Sciences, Mid Sweden University, Östersund, Sweden; ${ }^{2}$ Institution of Health Care Sciences, Ersta Sköndal Bräcke University College, Stockholm, Sweden; ${ }^{3}$ National Center for Disaster Psychiatry, Department of Neuroscience, Uppsala University, Uppsala, Sweden; ${ }^{4}$ Department of Women and Child's Health, Karolinska Institute, Stockholm, Sweden; ${ }^{5}$ Advanced Pediatric Home Care, Karolinska University Hospital, Stockholm, Sweden; ${ }^{6}$ School of Education, Health and Social Studies, Dalarna University, Falun, Sweden and ${ }^{7}$ Center for Clinical Research (CKF), Dalarna, Sweden
\end{abstract}

\begin{abstract}
Objective. The aim of the study was to explore the proportion of adult patients and next-ofkin who had end-of-life (EOL) discussions and associated factors.

Method. A retrospective nationwide registry study was reported with data from the Swedish Register of Palliative Care. All patients in Sweden in hospitals, nursing homes, own homes, community, and palliative care units during 2015-2017 and their next-of-kin were included. Data were reported to the register by healthcare staff, based on diseased patients' records regarding their last days of life, and were voluntary. Descriptive statistics illustrated the proportion of patients/next-of-kin who had EOL discussions and logistic regressions were used to examine associated factors.

Results. About half of the patients (46\%) did have an EOL discussion, but a third (32\%) did not. Associated factors of those who did not have an EOL discussion were dementia (48.5\%) or stroke $(47.5 \%)$, older age $(38.4 \%)$, being female (33.6\%), being cared for in a nursing home $(41.3 \%)$, or hospital $(40.3 \%)$, having lost decision-making ability months before death (58.9\%), and not having a documented decision to shift to EOL care $(82.7 \%)$. Younger patients diagnosed with cancer and cared for at a palliative unit were more likely to have EOL discussions. The regression analysis showed similar results for next-of-kin.

Significance of results. The result shows that not all patients with palliative care needs have equal access to EOL discussions, despite efforts at a national level and the recognized benefits of timely communication about the EOL care. Further efforts must be made to achieve EOL discussions for all patients.
\end{abstract}

\section{Introduction}

For healthcare professionals, palliative care is an interdisciplinary approach to provide the best available care and support (Vanderhaeghen et al., 2018). The approach enables patients and next-of-kin to be involved in the care process and decision-making, with communication and interpersonal relationships being cornerstones in this. A number of areas for improvement in palliative end-of-life (EOL) care have been identified in Sweden. These areas relate to the assessment of oral health and pain, and the prescription of anti-anxiety drugs and opioids for pain, pressure ulcer management and EOL discussions (The Swedish National Board of Health and Welfare [SNBHW], 2017).

Early integration of palliative care is highlighted (van der Steen et al., 2013) and may contribute to successful EOL discussions with patients and next-of-kin. During such discussions, important issues related to symptoms, emotions, and existential issues should be discussed continuously and in a timely manner (Udo et al., 2017; Hagan Thomas et al., 2019). Guidelines emphasize that all patients are entitled to information and opportunities for discussion during the care process, e.g., about transitioning from curative treatment to increased focus on palliative care and on a late palliative phase when imminent death is expected (Palliative Care Competence Framework Steering Group, 2014). These discussions with a patient and next-of-kin are similar to advanced care planning and include information, care planning and discussions about prognosis, goals of care, consent to treatment, and EOL decision-making (Sekse et al., 2018).

The majority of patients with progressive cancer think that it is the physician's responsibility to initiate EOL discussions (Bergenholtz et al., 2019). Discussions should be interdisciplinary, with a registered nurse present to provide person-centered care supporting the patient and minimize concerns and misunderstandings (Anderson et al., 2019). 
Barriers to EOL discussions include lack of time and privacy, lack of training, poor timing and readiness, prognostic uncertainty, and the fear of initiating EOL discussions (Udo et al., 2017; Doubal et al., 2018; Sekse et al., 2018). In a retrospective record review in nursing homes, it was found that EOL discussions with patients were not documented in any of the 100 patient records included. However, next-of-kin were informed about deterioration and what to expect in the near future (Høgsnes et al., 2016).

In recent years, the trend has been that EOL discussions have increased in frequency, but this differs between diagnoses and age groups (Martinsson et al., 2012). Old age may be a risk of not having EOL discussions (Lindskog et al., 2015). Which people are considered "old" is a complex and multidimensional judgment, but may be related to when a person is entitled to state pensions (United Nations, 2012). There are also geographical differences, despite EOL discussions being considered important and recommended in national guidelines (SNBHW, 2016).

The goal of having a national register like the SRPC is to enable scrutinization of palliative care. The register contains rich nationwide data from various care and geographical settings. The SRPC comprises information about several aspects of palliative care, including EOL discussions, that facilitate evaluations and enable healthcare institutions' follow-up of quality of care as well as research based on the register data (Lindskog et al., 2015; Elmstedt et al., 2019; Lövgren et al., 2019).

To ensure equal and high-quality palliative care where information is communicated with the patients and next-of-kin, it is important to continue the efforts to systemize EOL discussions. Therefore, the aim of this study was to explore the proportion of adult patients and next-of-kin who, according to the SRPC, had or did not have EOL discussions, and associated factors.

\section{Methods}

\section{Design and study population}

This nationwide register study was based on data from the SRPC database. It included all deaths in Sweden that were reported to the register during 2015-2017 $(n=177,921)$. The SRPC covered $55-66 \%$ of all deaths in Sweden during these 3 years (2015: $66 \%$; 2016: $64 \%, 2017: 55 \%)$. This study is a part of a larger project about communication in palliative care in collaboration between Ersta Sköndal Bräcke University College, Dalarna University, and Mid Sweden University.

\section{Measurement}

The SRPC comprises information about various aspects of palliative care and a questionnaire with 29 items that has been created specifically for the register based on the register was used in this study (Lundström et al., 2012). Data are reported to the register by healthcare staff and are voluntary. The findings should be applicable in clinical praxis. In this paper, the following data were used: patient age, sex, diagnosis, place of death, if there was a documented decision by the physician that care be shifted to EOL care (yes/no), how long before death the person lost the ability to express his or her will and participate in decisions about the content of medical care, if the person had an individually adapted and documented EOL discussion that he/she was in the final stages of life and that the care was focused on the quality of life and symptom relief (yes/no), and if the person's next-of-kin had an individually adapted and documented EOL discussion that the person was in the final stages of life and that the care was focused on the quality of life and symptom relief (yes/no).

\section{Data analysis}

Descriptive statistics using IBM SPSS statistics version 25 with mean, median, max-min, and standard deviation (SD) values for continuous variables, such as age (years), sex (male/female), diagnosis (cancer, heart disease, multiple diseases, dementia, lung disease, and stroke), place of death (hospital, nursing home, home, specialized inpatient palliative care unit, or other place), and percentages for categories were compiled for this study, as well as the proportion of patients and next-of-kin having had an EOL discussion. The outcomes were analyzed with two logistic regressions (enter method) with patients having had an EOL discussion and next-of-kin having had an EOL discussion, respectively, as the dependent variable. Predictors, including age, sex, diagnosis, place of death, if a physician had assessed that care be shifted to EOL care (yes/no), and how long before death the patient lost the ability to make decisions about the content of medical care (maintained, hours, days, weeks, and months), were documented. The relative risks were estimated using odds ratios with $95 \%$ confidence intervals.

\section{Ethical considerations}

The study followed the ethical principles of the Helsinki Declaration (Helsinki Declaration, 1964) and was approved by the Ethics Review Board in Stockholm, Sweden (Dnr: 2019-02617).

\section{Results}

\section{Sociodemographic characteristics}

The mean age in the sample was 81.8 years (median age 84 ); the youngest person was 18 years and the oldest 113 years. A majority were over 85 years of age and female. The most common diagnoses were cancer, heart disease, lung disease, multiple diseases, dementia, and stroke. Most patients died in a nursing home or hospital, with only a small proportion of the patients having died at home. A majority of the patients were still able to make decisions about the medical care content days before death and were informed about the transition to EOL care (Table 1).

\section{EOL discussion and associated factors}

Less than half (34\%) of the patients had not had a documented EOL discussion with a physician in the last days of life (Figure 1). The corresponding figure for next-of kin was $14 \%$ (Figure 2).

Almost half of the patients and a majority of the next-of-kin had an EOL discussion with a physician (46\% vs. 66\%). According to the logistic regression analysis (Table 2), patients who had not had an EOL discussion were predicted by older age, diagnosis (dementia or stroke), and place of death (dying in the hospital).

Those who lost their ability to make decisions months before death were more likely not to have had an EOL discussion, as were those who did not have a documented decision that care be shifted to EOL care. Compared with dying at a nursing home, there were several places of death that were significant predictors of having had an EOL discussion. The strongest predictors 
Table 1. Patients' sociodemographic characteristics $(N=177,921)$

\begin{tabular}{|c|c|}
\hline \multicolumn{2}{|l|}{ Background data } \\
\hline Age (years), mean (SD) & $81.8(11.9)$ \\
\hline Median & 84.0 \\
\hline Min-max & $18-113$ \\
\hline Age group (years) & $n(\%)$ \\
\hline $18-39$ & $884(0.5)$ \\
\hline $40-65$ & $14,601(8.2)$ \\
\hline $66-84$ & $75,594(42.5)$ \\
\hline$<85$ & $86,842(48.8)$ \\
\hline \multicolumn{2}{|l|}{ Sex } \\
\hline Male & $81,507(45.8)$ \\
\hline Female & $96,414(54.2)$ \\
\hline \multicolumn{2}{|l|}{ Diagnosis } \\
\hline Cancer & $60,669(34.1)$ \\
\hline Heart disease & $52,839(29.7)$ \\
\hline Multiple diseases & $46,880(26.3)$ \\
\hline Dementia & $36,089(20.3)$ \\
\hline Lung disease & $18,530(10.4)$ \\
\hline Stroke & $16,781(9.4)$ \\
\hline \multicolumn{2}{|l|}{ Place of death } \\
\hline Nursing home & $63,223(35.5)$ \\
\hline Hospital ward & $59,437(33.4)$ \\
\hline Palliative care unit hospital & $19,480(10.9)$ \\
\hline Short-term care & $13,085(7.4)$ \\
\hline Own home - specialized care & $9,865(5.5)$ \\
\hline Own home - general & $7,314(4.1)$ \\
\hline Own home - municipality care & $2,814(1.4)$ \\
\hline Other & $3,036(1.7)$ \\
\hline \multicolumn{2}{|c|}{ Assessment that care shifted to EOL care } \\
\hline Yes & $82,422(46.3)$ \\
\hline No & $56,909(32.0)$ \\
\hline Missing & $38,590(21.7)$ \\
\hline \multicolumn{2}{|c|}{ How long before death the patient lost decision-making ability } \\
\hline Maintained & $14,114(7.9)$ \\
\hline Hours & $32,991(18.5)$ \\
\hline Days & $66,273(49.8)$ \\
\hline Weeks & $13,923(10.5)$ \\
\hline Months & $19,889(14.9)$ \\
\hline Missing & $30,731(17.2)$ \\
\hline
\end{tabular}

of having had an EOL discussion were dying at home with support from specialized palliative home care or dying at a palliative care unit, if it was documented in the patient's record that care had shifted to EOL care, and if the patient had cancer. Next-of-kin who had not had an EOL discussion were predicted by older age of the patient, diagnosis (heart disease or lung

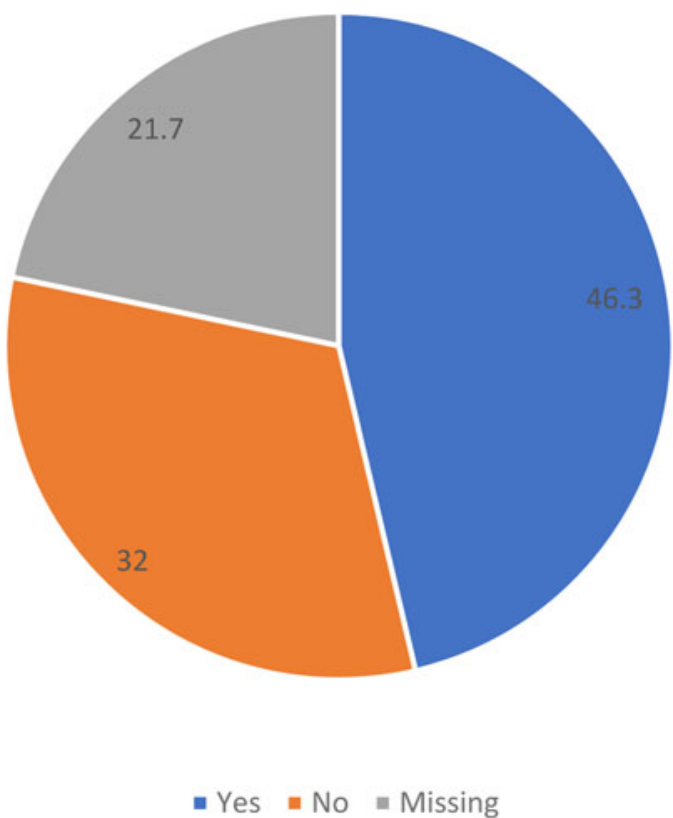

Fig. 1. Proportion of patients with EOL discussions in the years 2015-2017.

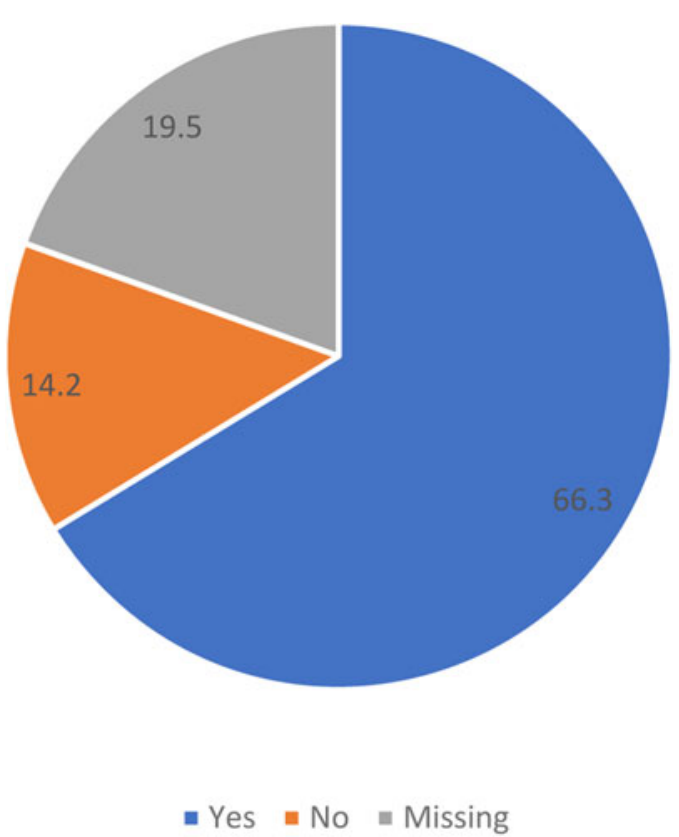

Fig. 2. Proportion of next-of-kin with EOL discussions in the years 2015-2017.

disease), no documented decision that care be shifted to EOL care, and place of death (own home with municipality care or short-term care). The strongest predictor of the next-of-kin having had an EOL discussion was that care had shifted to EOL care. Of the diagnoses, cancer was the strongest predictor of next-of-kin having had an EOL discussion.

\section{Discussion}

The proportions of adult patients and next-of-kin who do not have an EOL discussion and associated factors are relatively 
Table 2. Patients with/without EOL discussions and multivariate associations between patient-/care-related factors and EOL discussions with patients and next-of-kin, respectively

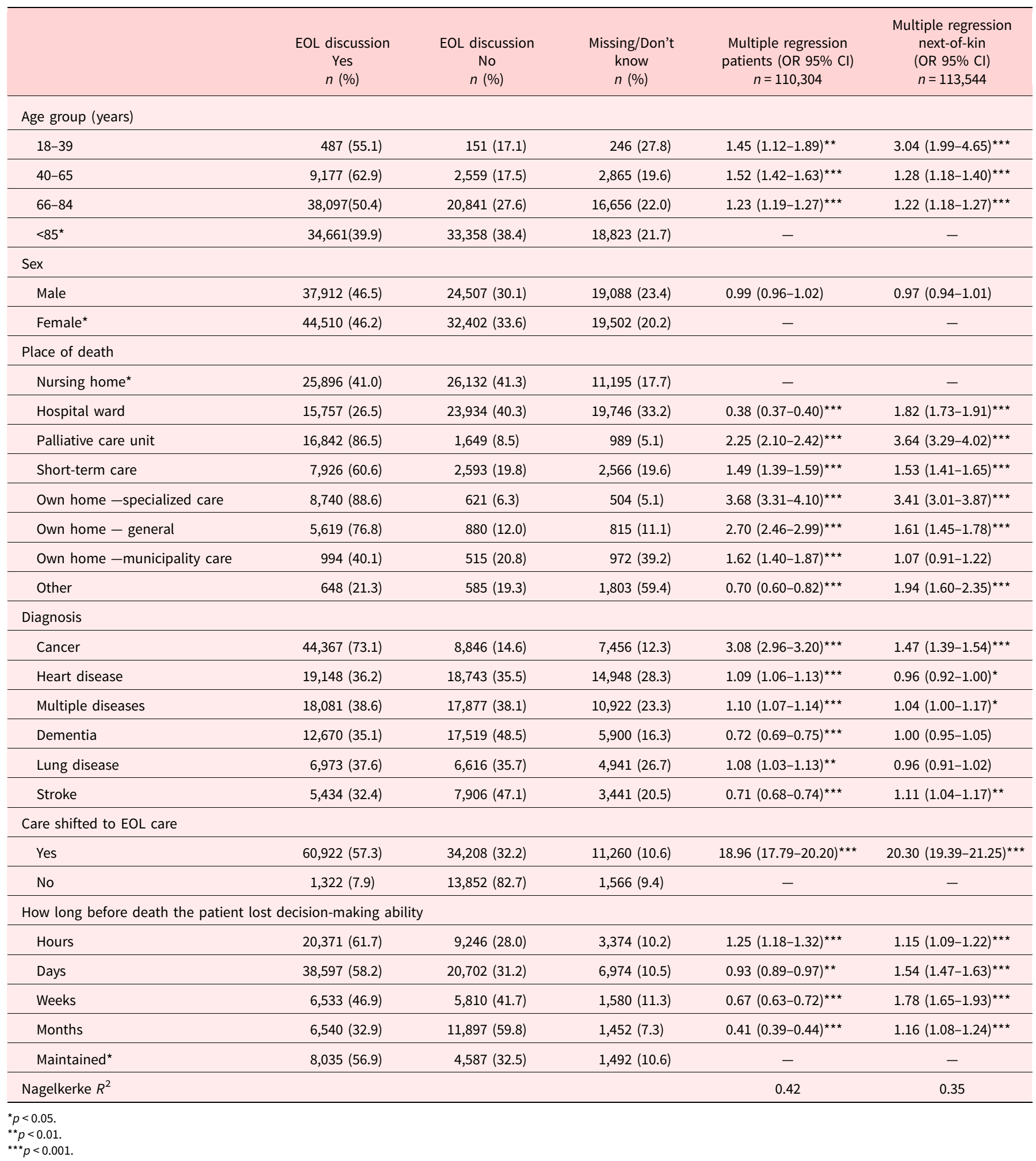

unknown. Our study included 177,921 registrations in the SRPC of patients who died during the period 2015-2017. Based on this extensive data, fewer of the patients who had EOL discussions were older and female, diagnosed with dementia or stroke, and cared for in a nursing home or hospital. A larger proportion of the patients and next-of-kin who had EOL discussions had cancer or had a decision made by their physician that care be shifted to EOL care documented in their patient record.

Our study confirmed previous findings that EOL discussions are not implemented in all care contexts and are not provided to patients on equal terms. Adequate and consistent documentation related to EOL care goals and decision-making has an impact 
on the quality of care, including EOL discussions (Bloomer et al., 2018). This was particularly apparent in the present study among older patients diagnosed with stroke or dementia, who died in a nursing home or hospital, or if the shift to EOL care was undocumented. Previous register-based studies show that patients with lung disease in specialist palliative care had EOL discussions more often than those in nursing homes (Henoch et al., 2019). It has also been reported that a documented EOL discussion is a factor that relieves symptoms for persons cared for in nursing homes and their next-of-kin (Andersson et al., 2018). On the other hand, having EOL discussions is not more common in regions with fully developed palliative care compared with regions with less developed palliative care (Schelin et al., 2018). This support the importance of improving palliative care including EOL discussions in, for example, nursing home settings (Smedbäck et al., 2017). Significantly fewer EOL discussions were held with patients with an incurable illness in their last week of life during the COVID-19 pandemic in 2020 compared with 2019 (Strang et al., 2020), which further increased inequality.

Old age is a predictor for not having EOL discussions, and for patients and next-of-kin not getting information about imminent death (Lindskog et al., 2015). This is particularly common if the older person has dementia, is dying in hospital (Martinsson et al., 2020), and has difficulties understanding the prognosis or limitations of life support care (Ethier et al., 2018). Although evidence is limited, studies have shown that persons with dementia are a neglected group when it comes to palliative care, including EOL discussions (Ngo and Holroyd-Leduc, 2015; Erel et al., 2017; Piers et al., 2018); there is increased recognition of their need and eligibility for such care (Erel et al., 2017). This makes the presence of next-of-kin, and their role in the communication process, even more important (Ngo and Holroyd-Leduc, 2015). The lack of EOL discussions for dying persons with dementia suggests that the EOL discussion process and advanced care planning should be initiated at an earlier stage with persons with dementia and next-of-kin, to better prepare them for EOL care. If information is given early on, these persons would most likely be able to receive the information about EOL issues and participate in the communication process, despite illness progression.

EOL discussions are of most importance to patients when receiving appropriate symptom management and to avoid unnecessary hospitalization or treatment against the person's preferences and wishes (Jethwa and Onalaja, 2015). Considering that persons with dementia may not have the cognitive ability to discuss EOL plans (Brooke and Kirk, 2014), emphasis should be on how to support staff to achieve successful EOL discussions where next-of-kin are included - not on if it should be done (Høgsnes et al., 2014). Information and communication to next-of-kin is crucial both for their own well-being and for making informed decisions in the best interests of their loved ones (Dening et al., 2017; Bosisio et al., 2018). Applying a palliative care philosophy in nursing homes may support a next-of-kin's existential life situation, which often becomes more difficult after their loved one has been relocated to a nursing home (Brooke and Kirk, 2014; Høgsnes et al., 2014). Person-centered care may not be enough for older persons, especially when diagnosed with dementia, making the family's role vital (Feinberg, 2014). Family-centered care including a wider family network has been suggested as beneficial in palliative care for persons with dementia (Broady et al., 2018; Hao and Ruggiano, 2020). This approach is widely used in pediatric care, and there is now a growing interest in implementing family-centered care also in adult care for the most vulnerable (Feinberg, 2014; Hao and Ruggiano, 2020).

\section{Limitations of the study}

This retrospective nationwide registry study contributes knowledge about factors influencing EOL discussions. The strengths are that it included all deaths in Sweden reported to the SPCR during 2015-2017, and specifies the proportion of EOL discussions provided to patients and next of kin. However, underlying factors as geographical locations are not examined, and that the palliative care knowledge and competence among professionals is unknown might have an impact on factors associated with EOL discussions. Furthermore, staff who register data in the SRPC have varying knowledge about the patients' last days of life, and data should therefore be interpreted with caution.

\section{Conclusion and clinical implications}

Despite the benefits of timely communication about EOL care, dying patients do not have equal access to communication about EOL issues. Though not all patients and next-of-kin may wish to participate in EOL discussions, they must still be invited and given the opportunity to choose, as part of high-quality palliative care. Our extensive nationwide data supported previous findings that EOL discussions seem to be a challenge, as they are not equally and systematically implemented in all care settings and to all patients, regardless of diagnosis or age. Based on the results in this study, further efforts must be made, so that neglected patients and next of-kin can receive the EOL discussions they are entitled to, on equal terms.

Funding statement. Mid Sweden University and Ersta Sköndal Bräcke University College provided financial support for publication of this article.

Conflicts of interest. None declared.

\section{References}

Anderson RJ, Bloch S, Armstrong M, et al. (2019) Communication between healthcare professionals and relatives of patients approaching the end-of-life: A systematic review of qualitative evidence. Palliative Medicine 33(8). doi:10.1177/0269216319852007.

Andersson S, Årestedt K, Lindqvist O, et al. (2018) Factors associated with symptom relief in end-of-life care in residential care homes: A national register-based study. Journal of Pain and Symptom Management 55(5). doi:10.1016/j.jpainsymman.2017.12.489.

Bergenholtz H, Timm HU and Missel M (2019) Talking about end of life in general palliative care - what's going on? A qualitative study on end-of-life conversations in an acute care hospital in Denmark. BMC Palliative Care 18(1), 1-14. doi:10.1186/s12904-019-0448-z.

Bloomer MJ, Botti M, Runacres F, et al. (2018) Communicating end-of-life care goals and decision-making among a multidisciplinary geriatric inpatient rehabilitation team: A qualitative descriptive study. Palliative Medicine 32(10). doi:10.1177/0269216318790353.

Bosisio F, Jox JR, Jones L, et al. (2018) Planning ahead with dementia: what roles can advance care planning play? A review on opportunities and challenges. Swiss Medical Weakly 148. doi:10.4414/smw.2018.14706.

Broady T, Saich F and Hinton T (2018) Caring for a family member or friend with dementia at the end of life: A scoping review and implications for palliative care practice. Palliative Medicine 32(3). doi:10.1177/ 0269216317748844 .

Brooke J and Kirk M (2014) Advance care planning for people living with dementia. British Journal of Community Nursing 19(10). doi:10.12968/ bjcn.2014.19.10.490. 
Dening KH, King M, Jones L, et al. (2017) Healthcare decision-making: Past, present and future, in light of a diagnosis of dementia. International Journal of Palliative Nursing 23(1). doi:10.12968/ijpn.2017.23.1.4.

Doubal F, Cowey E, Bailey F, et al. (2018) The key challenges of discussing end-of-life stroke care with patients and families: A mixed-methods electronic survey of hospital and community healthcare professionals. The Journal of the Royal College of Physicians of Edinburgh 48(3). doi:10.4997/JRCPE.2018.305.

Elmstedt S, Mogensen H, Hallmans DE, et al. (2019) Cancer patients hospitalised in the last week of life risk insufficient care quality - A populationbased study from the Swedish register of palliative care. Acta Oncologica 58(4). doi:10.1080/0284186x.2018.1556802.

Erel M, Marcus EL and Dekeyser-Ganz F (2017) Barriers to palliative care for advanced dementia: A scoping review. Annual in Palliative Medicine 6(4). doi:10.21037/apm.2017.06.13.

Ethier JL, Paramsothy T, You J, et al. (2018) Perceived barriers to goals of care discussions with patients with advanced cancer and their families in the ambulatory setting: A multicenter survey of oncologists. Journal of Palliative Care 33(3). doi:10.1177/0825859718762287.

Feinberg LF (2014) Moving toward person- and family-centered care. Public Policy \& Aging Report 24(3). doi:10.1093/ppar/pru027.

Hagan Thomas T, Jackson V, Carlson H, et al. (2019) Communication differences between oncologists and palliative care clinicians: A qualitative analysis of early, integrated palliative care in patients with advanced cancer. Journal of Palliative Medicine 22(1). doi:10.1089/jpm.2018.0092.

Hao Z and Ruggiano N (2020) Family-centeredness in dementia care: What is the evidence. Social Work and Health Care 59(1). doi:10.1080/ 00981389.2019 .1690089$.

Helsinki Declaration (1964) Human experimentation: Code of ethics of W.M.A. British Medical Journal 2. doi:10.1136/bmj.2.5402.177.

Henoch I, Strang P, Löfdahl CG, et al. (2019) Equal palliative care for patients with COPD? A nationwide register study. Uppsala Journal of Medical Sciences 124(2). doi:10.1080/03009734.2019.1586803.

Høgsnes L, Melin-Johansson C, Norbergh KG, et al. (2014) The existential life situations of spouses of persons with dementia before and after relocating to a nursing home. Ageing \& Mental Health 18(2), 152-160. doi:10.1080/13607863.2013.818100.

Høgsnes L, Danielson E, Norbergh KG, et al. (2016) Healthcare professionals' documentation in nursing homes when caring for patients with dementia in end of life - a retrospective records review. Journal of Clinical Nursing 25(11-12), 1663-1673. doi:10.1111/jocn.13184.

Jethwa KD and Onalaja $\mathbf{O}$ (2015) Advance care planning and palliative medicine in advanced dementia: A literature review. BJ Psychological Bulletin 39, 74-78.

Lindskog M, Tavelin B and Lundstrom S (2015) Old age as risk indicator for poor end-of-life care quality - A population-based study of cancer deaths from the Swedish register of palliative care. European Journal of Cancer Care 51(10), 1331-1339.

Lövgren M, Melin-Johansson C, Udo C, et al. (2019) Telling the truth to dying children - End-of-life communication with families. Acta Paediatrica 108. doi:10.1111/apa.14935.
Lundström S, Axelsson B, Heedman PA, et al. (2012) Developing a national quality register in end-of-life care: The Swedish experience. Palliative Medicine 26(4). doi:10.1177/0269216311414758.

Martinsson L, Fürst CJ, Lundström S, et al. (2012) Registration in a quality register: A method to improve end-of-life care - A cross-sectional study. BMJ Open 2(4), 1-7.

Martinsson L, Lundström S and Sundelöf J (2020) Better quality of end-of-life care for persons with advanced dementia in nursing homes compared to hospitals: A Swedish national register study. BMC Palliative Care 19. doi:10.1186/s12904-020-00639-5.

Ngo J and Holroyd-Leduc JM (2015) Systematic review of recent dementia practice guidelines. Age and Ageing 44, 25-33.

Palliative Care Competence Framework Steering Group (2014) Palliative Care Competence Framework. Dublin: Health Service Executive.

Piers R, Albers G, Gilissen J, et al. (2018) Advance care planning in dementia: Recommendations for healthcare professionals. BMC Palliative Care 17. doi:10.1186/s12904-018-0332-2.

Schelin ME, Sallerfors B, Rasmussen BH, et al. (2018) Quality of care for the dying across different levels of palliative care development: A population-based cohort study. Palliative Medicine 32(10). doi:10.1177/0269216318801251.

Sekse R, Hunskår I and Ellingsen S (2018) The nurse's role in palliative care: A qualitative meta-synthesis. Journal of Clinical Nursing 27. doi:10.1111/ jocn.13912.

Smedbäck J, Öhlén J, Årestedt K, et al. (2017) Palliative care during the final week of life of older people in nursing homes: A register-based study. Palliative and Support Care 15(4), 417-424. doi:10.1017/S1478951516000948.

Strang P, Bergström J, Martinsson L, et al. (2020) Dying from COVID-19: Loneliness, end-of-life discussions, and support for patients and their families in nursing homes and hospitals. A national register study. Journal of Pain and Symptom Management 60(4), 2-13. doi:10.1016/ j.jpainsymman.2020.07.020.

The Swedish National Board of Health and Welfare (2016) National guidelines Evaluation. Palliative care at the end of life: Indicators and basis for assessments. Available from: https://www.socialstyrelsen.se/globalassets/sharepoint-dokument/artikelkatalog/nationella-riktlinjer/2016-12-12.pdf. [In Swedish].

The Swedish National Board of Health and Welfare (2017) National Guidelines - Target Levels in Palliative Care at the End of Life. Target Levels for Indicators. Stockholm: The Swedish National Board of Health and Welfare. [In Swedish].

Udo C, Lövgren M, Lundquist G, et al. (2017) Palliative care physicians' experiences of end-of-life communication: A focus group study. European Journal of Cancer Care 27(1). doi:10.1111/ecc.12728.

United Nations (2012) UNFPA Report. Available from: https://www.unfpa. org/sites/default/files/resource-pdf/UNFPA-Report-Chapter1.pdf.

Vanderhaeghen B, Bossuyt I, Opdebeeck S, et al. (2018) Toward hospital implementation of advance care planning: Should hospital professionals be involved? Qualitative Health Research 28(3), 456-465.

van der Steen JT, Radbruch L, Hertogh CM, et al. (2013) White paper defining optimal palliative care in older people with dementia: A Delphi study and recommendations from the European association for palliative care. Palliative Medicine 28(3), 197-209. 